\title{
Metabolic Syndrome and Male Fertility
}

\author{
Ana Dias Martins ${ }^{1,2}$ (D), Ahmad Majzoub ${ }^{3}$ (D) Ashok Agawal ${ }^{1}$ (D) \\ ${ }^{1}$ American Center for Reproductive Medicine, Department of Urology, Cleveland Clinic, Cleveland, OH, USA, ${ }^{2}$ Department of Microscopy, \\ Laboratory of Cell Biology and Unit for Multidisciplinary Research in Biomedicine, Abel Salazar Institute of Biomedical Sciences (ICBAS), \\ University of Porto, Porto, Portugal, ${ }^{3}$ Department of Urology, Hamad Medical Corporation and Weill Cornell Medicine-Qatar, Doha, Qatar
}

\begin{abstract}
Metabolic syndrome (MetS) represents a cluster of conditions that have a negative impact on human health overall. Its prevalence has been rapidly increasing worldwide and has coincided with a global decrease in birth rates and fertility potential. This review aims to address this observation through studying the relationship between MetS and male reproductive health. The effects of obesity, dyslipidemia, hypertension, and insulin resistance on male fertility were examined and supporting evidence explaining the pathophysiology of sperm dysfunction with each MetS component were described. Adopting a healthy lifestyle appears to be the single most important intervention to prevent the unwanted effects of MetS on men's health and fertility. Further studies addressing the components of MetS and their impact on male reproduction are required to enhance our understanding of the underlying pathophysiology and to propose new methods for therapeutic intervention.
\end{abstract}

Keywords: Dyslipidemias; Glucose intolerance; Hypertension; Infertility, male; Metabolic syndrome; Obesity

This is an Open Access article distributed under the terms of the Creative Commons Attribution Non-Commercial License (http://creativecommons.org/licenses/by-nc/4.0) which permits unrestricted non-commercial use, distribution, and reproduction in any medium, provided the original work is properly cited.

\section{INTRODUCTION}

Metabolic syndrome (MetS) describes a cluster of abnormalities including obesity, dyslipidemia, hypertension, and insulin resistance. Its discovery goes back to early twentieth century when Kylin [1] first described a combination of metabolic disturbances, namely hypertension, hyperglycemia and gout. In the 1940s, Vague [2] noticed an association between upper body adiposity, hypertension and diabetes, which allowed Haller and Hanefeld [3], in 1975, to coin the term MetS, defining it as a combination of simultaneous risk factors (diabetes, cardiovascular disease) that are hazardous to human health. Other nomenclatures came out in later years such as Syndrome X (1988) [4], the Deadly
Quartet (1989) [5], and the Insulin Resistance Syndrome (1992) [6]. Nevertheless, disparity still exists regarding the exact diagnostic criteria used to define MetS; therefore guidelines proposed by the International Diabetes Federation (IDF) [7], National Cholesterol Education Program Adult Treatment Panel III (NCEP ATP III) [8] and World Health Organization (WHO) [9] are commonly utilized to recognize this condition in clinical practice (Table 1).

The systemic nature of MetS motivated the investigation of its deleterious effects once it may potentially affect many aspects of human physiology. Male infertility is one condition that can be influenced by the subject's metabolic status. Recent evidence suggests that a direct association between the different com-

Received: Jun 28, 2018 Accepted: Jul 5, 2018 Published online Oct 22, 2018

Correspondence to: Ashok Agarwal iD https://orcid.org/0000-0003-0585-1026

American Center for Reproductive Medicine, Department of Urology, Cleveland Clinic, 10681 Carnegie Avenue, Cleveland, OH 44195, USA.

Tel: +1-216-444-9485, Fax: +1-216-445-6049, E-mail: agarwaa@ccf.org 
Table 1. Criteria for the classification of metabolic syndrome

\begin{tabular}{|c|c|c|c|}
\hline & WHO [9] & NCEP ATP III [8] & IDF [7] \\
\hline Central obesity & $\begin{array}{l}\text { - Men: waist/hip ratio }>0.9 \\
\text { - Women: waist/hip ratio }>0.85 \\
\text { - And or } \mathrm{BMI}>30 \mathrm{~kg} / \mathrm{m}^{2}\end{array}$ & $\begin{array}{l}\text { - Waist circumference: } \\
\text { - Men: } \geq 102 \mathrm{~cm} \\
\text { - Women: } \geq 88 \mathrm{~cm}\end{array}$ & $\begin{array}{l}\text { - Waist circumference has ethnicity } \\
\text { specific values. }\end{array}$ \\
\hline $\begin{array}{l}\text { Raised blood } \\
\text { pressure }\end{array}$ & $\bullet \geq 140 / 90 \mathrm{mmHg}$ & $\begin{array}{l}\text { - Treatment of previous diagnosed } \\
\text { hypertension or } \geq 130 / 80 \mathrm{mmHg}\end{array}$ & $\begin{array}{l}\text { - Treatment of previous diagnosed } \\
\text { hypertension or } \geq 130 / 85 \mathrm{mmHg}\end{array}$ \\
\hline Raised FPG & $\begin{array}{l}\text { - Impaired glucose tolerance } \\
\text { - Impaired fasting glucose } \\
\text { - Type } 2 \text { diabetes mellitus }\end{array}$ & \multicolumn{2}{|c|}{ - Previously diagnosed of type 2 diabetes mellitus or FPG test $\geq 100 \mathrm{mg} / \mathrm{dL}$} \\
\hline $\begin{array}{l}\text { Reduced HDL } \\
\text { cholesterol }\end{array}$ & $\begin{array}{l}- \text { Men: }<40 \mathrm{mg} / \mathrm{dL} \\
\text { - Women: }<50 \mathrm{mg} / \mathrm{dL}\end{array}$ & \multicolumn{2}{|c|}{$\begin{array}{l}\text { - Specific treatment for cholesterol or }<40 \mathrm{mg} / \mathrm{dL} \text { in men and }<50 \mathrm{mg} / \mathrm{dL} \\
\text { in women }\end{array}$} \\
\hline Triglycerides & $\cdot \geq 150 \mathrm{mg} / \mathrm{dL}$ & - Specific treatment for lowering the & ycerides or $\geq 150 \mathrm{mg} / \mathrm{dL}$ \\
\hline
\end{tabular}

WHO: World Health Organization, NCEP ATP III: National Cholesterol Education Program Adult Treatment Panel III, IDF: International Diabetes Federation, HDL: high-density lipoprotein-cholesterol, BMI: body mass index, FPG: fasting plasma glucose.

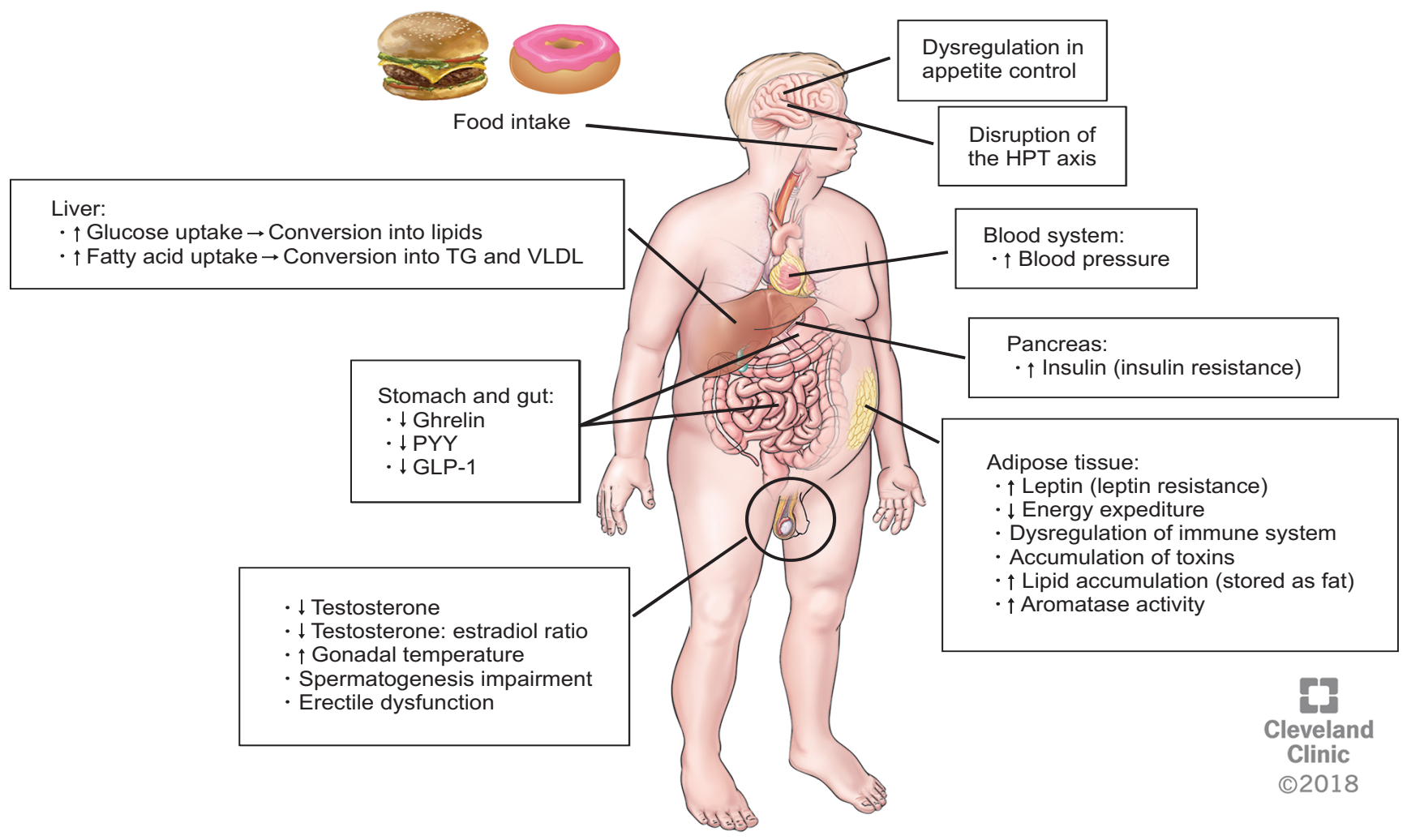

Fig. 1. Pathophysiology of metabolic syndrome, effects and consequences of each component (obesity, insulin resistance, dyslipidemia, and elevated blood pressure) in the human body. HPT: hypothalamic-pituitary-thyroid, TG: triglycerides, VLDL: very low density lipoproteins, PYY: peptide YY, GLP-1: glucagon like peptide-1, CCK: cholecystokinin.

ponents of MetS and sperm production and function exist. Infertility affects about $15 \%$ of couples attempting to conceive after 1 year of regular unprotected intercourse. Male factor contributes to $20 \%$ to $50 \%$ of the causes of infertility among couples. The increase in the prevalence of MetS perceived in recent years has coincided with a decrease in semen quality among adult males. It is therefore intuitive to investigate the available literature linking these two conditions together, which was the primary objective of this review article. 


\section{Men's Health}

\section{DEFINITIONS AND EPIDEMIOLOGY OF METABOLIC SYNDROME}

Various definitions for MetS exist and all of them are based on physiological parameters, such as obesity, glucose and lipid blood levels, and blood pressure [7-11] (Fig. 1). The WHO first developed its definition in 1998 [12]. Because insulin resistance was felt to be central to the pathophysiology of MetS, evidence for insulin resistance is an absolute requirement in the WHO definition, without it, even if all the other criteria were met, the patient would not have MetS (Table 1). The NCEP ATP III [8] criteria classifies an individual with MetS when he presents with three of the 5 components described in Table 1. MetS, according to IDF [7], is met when an individual presents with central obesity (high waist circumference [WC]) plus any two of the criteria present in Table 1.

The absence of a standardized definition for MetS is one of the reasons why it became difficult to have a clear estimate about its prevalence. Representations of the global patterns of the components of MetS in males has been published by the WHO (Fig. 2-5). These metabolic derangements are influenced by lifestyle factors, age, sex, and race and are increasing worldwide, thus becoming a subject of concern and an object of research

When analyzing the prevalence of MetS, it is necessary to take many factors into account. In younger generations, the prevalence of MetS is mainly influenced by the adopted diagnostic criteria followed by age and ethnicity (for review [13]). The prevalence of MetS is inversely related to the education level, the lifestyle (high fat diet and lack of exercise) and socioeconomic status. Rapid urbanization has been considered a principle factor for the increasing incidence of MetS (for review [13]). It is currently believed that approximately one in five US adults meet the criteria

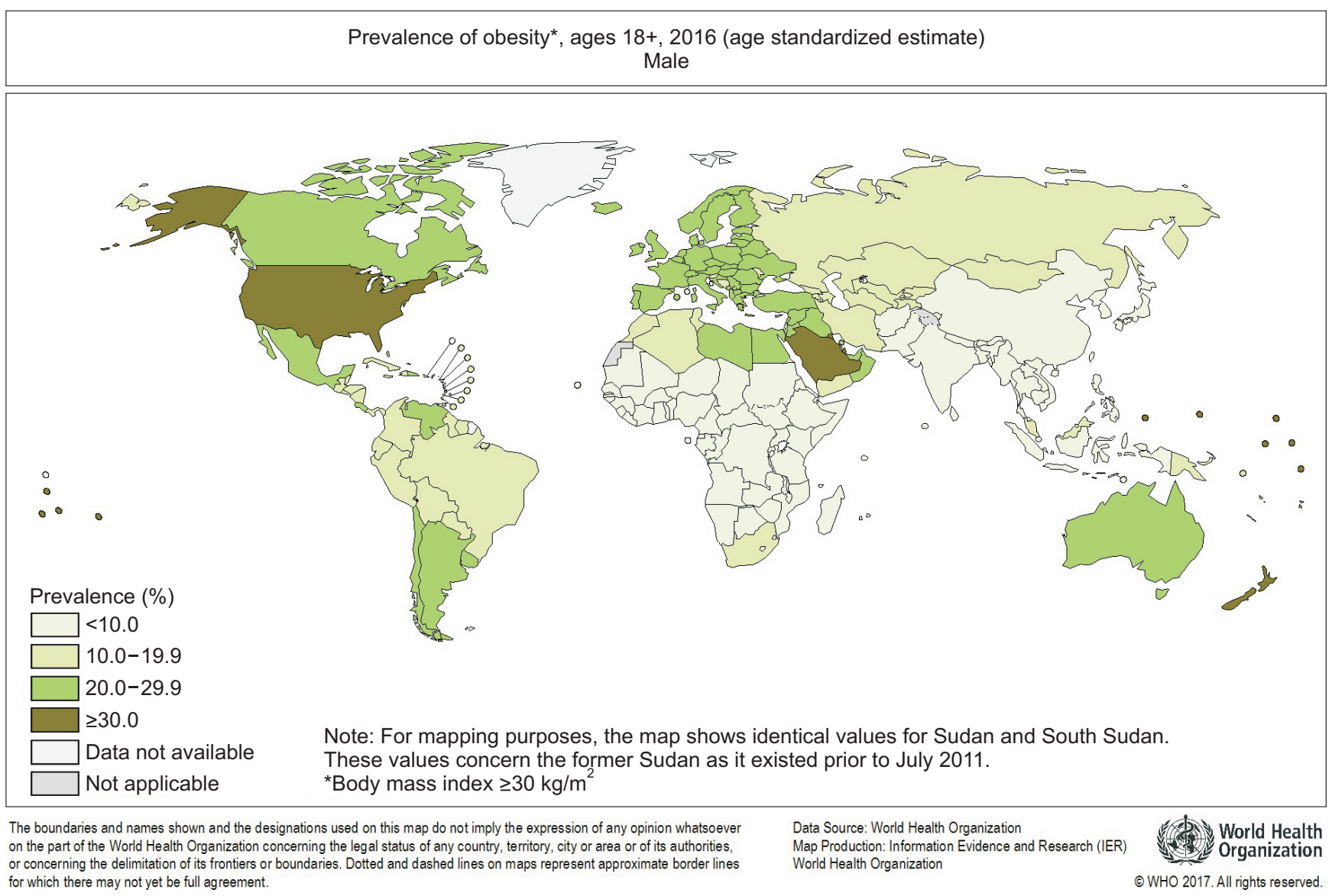

Fig. 2. Prevalence of obesity in male adults (18 years or older) according to World Health Organization (WHO) with data from 2016 (Data from Global Health Observatory Map Gallery, WHO with original copyright holder's permission; http://gamapserver.who.int/mapLibrary/Files/Maps/ Global_Obesity_2016_Male.png; accessed in 2018 June 25). 


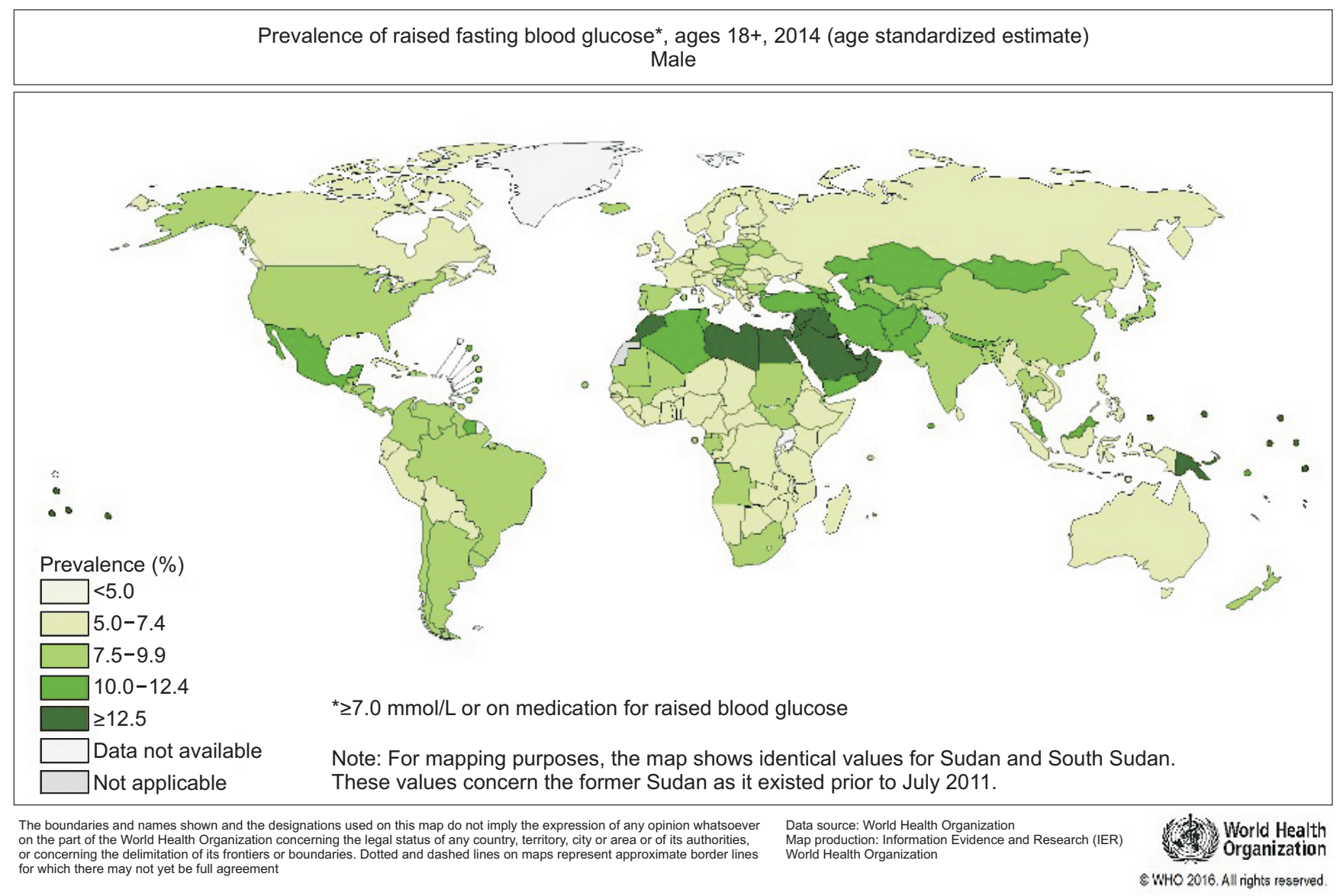

Fig. 3. Prevalence of raised fasting blood glucose in male adults (18 years or older) according to to World Health Organization (WHO) with data from 2014 (Data from Global Health Observatory Map Gallery, WHO with original copyright holder's permission; http://gamapserver.who.int/mapLibrary/Files/Maps/Global_BloodGlucosePrevalence_Male-2014.png; accessed in 2018 June 25).

for MetS [14]. The prevalence of MetS worldwide can go from $<10 \%$ to $84 \%$; this high variation is dependent on the geographic localization, age, race, and ethnicity, as well as the accepted definition [15]. Moreover, all the already mentioned factors, genetic background, family history of diabetes and smoking are additional risk factors that influence the prevalence of MetS and its components [15].

\section{THE LINK BETWEEN METABOLIC SYNDROME AND MALE FERTILITY}

Although each disease that is part of MetS definition has effects on male fertility separately, when put together, these metabolic elements can have additive effects on fertility. Studies exploring the effects of MetS on male fertility are recent (Fig. 6). In 2013, Lotti et al [16] studied the association between MetS and clinical characteristics of men of infertile couples. In this study, an age-adjusted model showed that MetS was associated with a decline in total testosterone without alterations in gonadotropin levels. The same study reported a negative correlation between the number of MetS components and progressive motility as well as normal morphology in a univariate analysis; however, adjusting the study for age and total testosterone, only normal morphology showed the same negative correlation. The risk of erectile dysfunction (ED) increased with the number of MetS factors, even after adjusting for age and testosterone levels. This study demonstrated an association between MetS and the presence of hypogonadism, decreased normal sperm morphology and $\mathrm{ED}$ in men of infertile couples. The same group, one year later [17], explored the association between MetS and prostatic abnormalities in infertile men. In an age adjusted model, the authors identified that insulin levels increased as a function of MetS components and showed an inverse correlation with total testosterone 


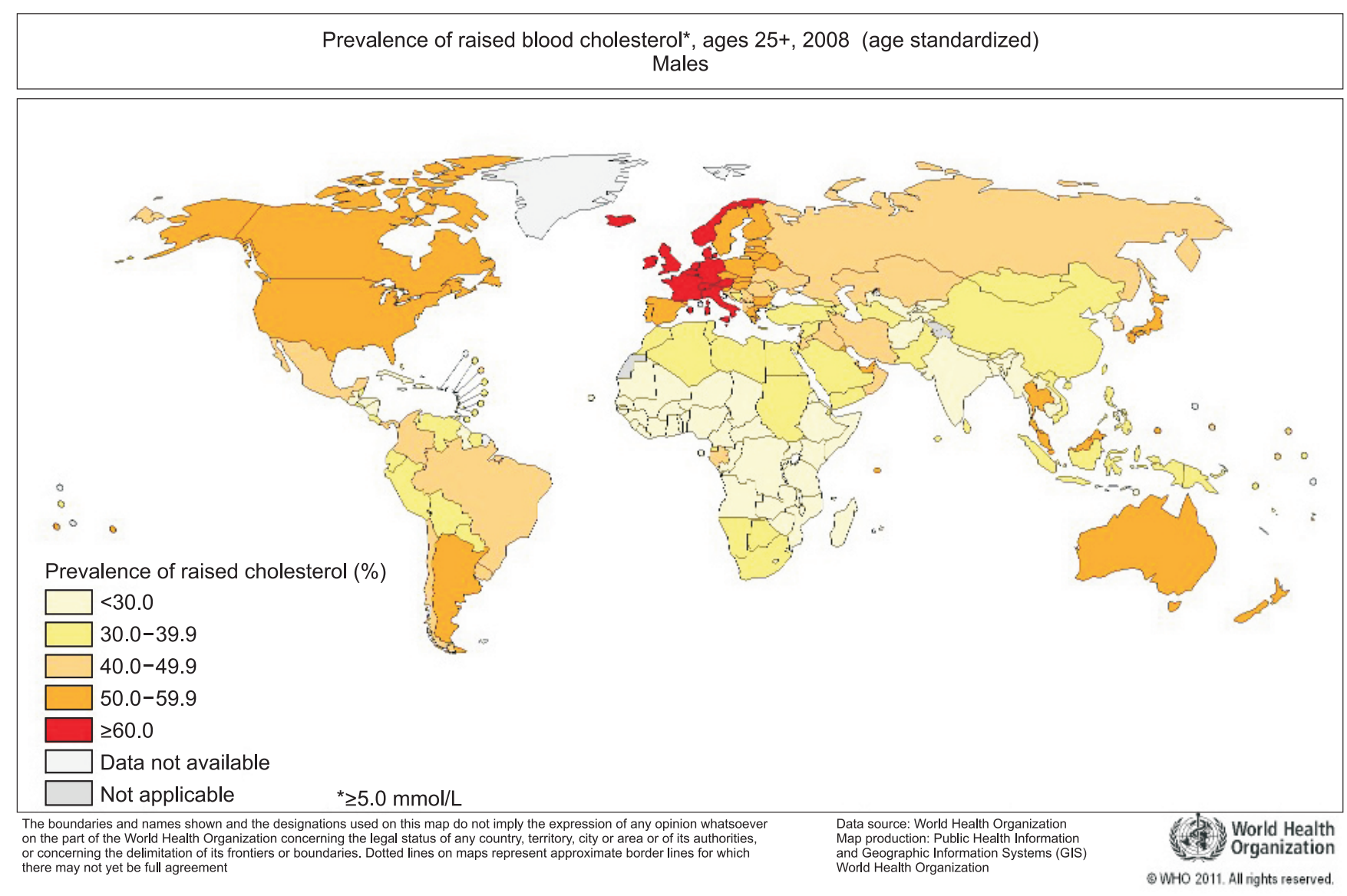

Fig. 4. Prevalence of raised blood cholesterol in male adults (25 years or older) according to World Health Organization (WHO) with data from 2008 (Data from Global Health Observatory Map Gallery, WHO with original copyright holder's permission; http://gamapserver.who.int/mapLibrary/Files/Maps/Global_BloodCholesterolPrevalence_Males_2008.png, accessed in 2018 June 25).

levels. This study also reported a negative correlation between MetS components and normal sperm morphology and a positive correlation between MetS components and interleukine-8 (a prostate inflammation marker), prostate total and transitional zone volume, arterial peak systolic velocity, texture homogeneity and calcification size in an age-testosterone-insulin adjusted model. Leisegang et al [18] compared male patients, with and without MetS, and reported lower sperm concentration, total sperm count, total motility, sperm viability, mitochondrial membrane potential, free testosterone and progesterone levels, and higher sperm DNA fragmentation in men with MetS. In 2016, Ventimiglia et al [19] examined men presenting with primary infertility with or without MetS according to the NCEPATPIII criteria. Compared with infertile men without MetS, infertile men with MetS were more likely to be hypogonadal, had lower levels of total testosterone sex hormone-binding globulin (SHBG), inhibin B and antiMüllerian hormone (AMH). However, no differences were found in semen parameters between the two groups [19]. On the other hand, a recent study compared semen and hormone parameters of fertile men to infertile men. Except for a significant negative association between MetS and total testosterone levels in both groups, the authors failed to reproduce a significant independent effect for MetS on major fertility parameters of both groups [20]. These studies suggest that MetS may carry a detrimental effect on important reproductive functions such as endocrine status or semen parameters and call for the development of further research of superior design to accurately determine this association.

\section{OBESITY AND MALE FERTILITY}

\section{An overview on obesity}

Obesity is classified according to body mass index (BMI) which was promoted by Ancel Keys in 1972 and describes a person's leanness based on their height 


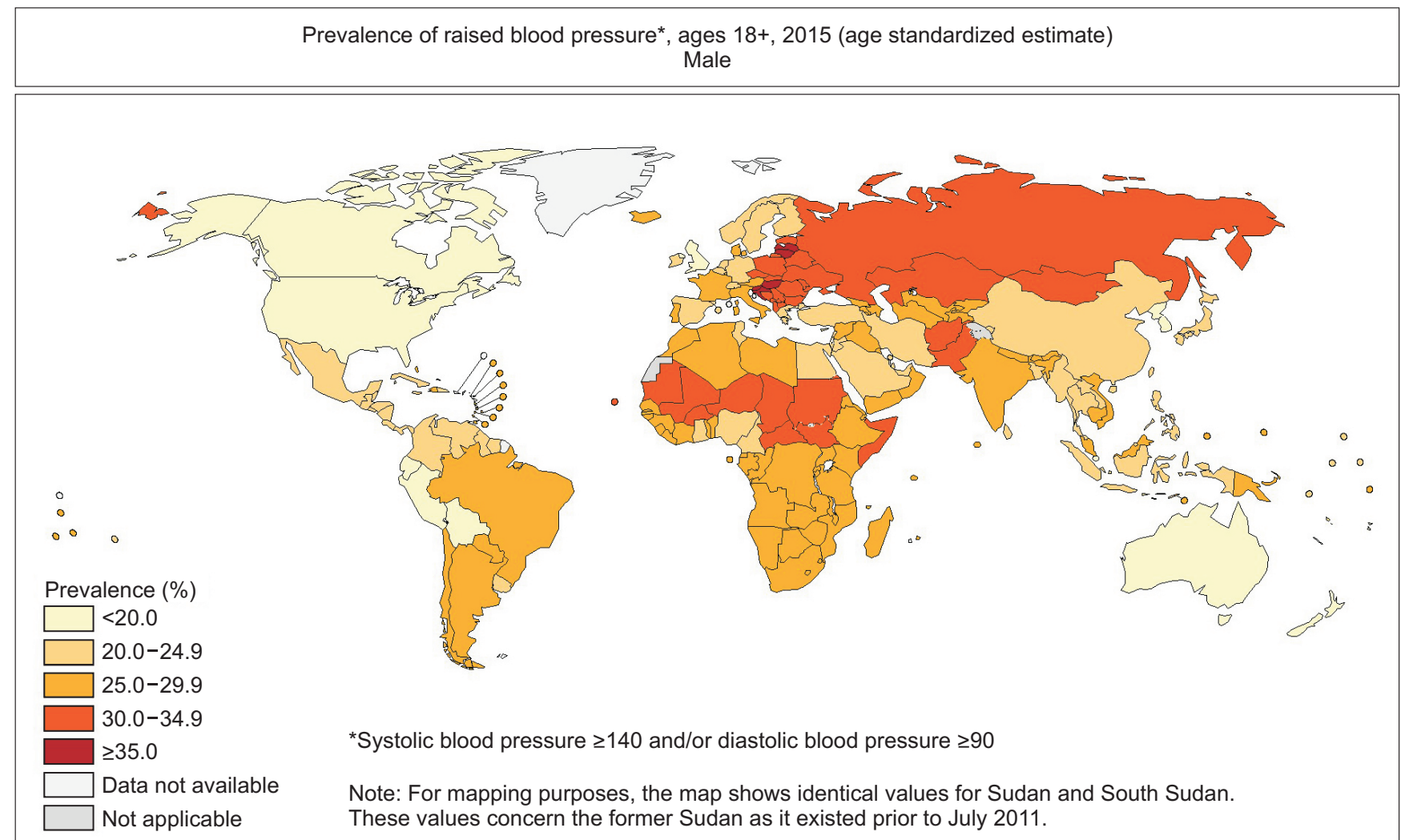

The boundaries and names shown and the designations used on this map do not imply the expression of any opinion whatsoever on the part of the World Health Organization concerning the legal status of any country, territory, city or area or of its authorities, or concerning the delimitation of its frontiers or boundaries. Dotted and dashed lines on maps represent approximate border lines for which there may not yet be full agreement.

Data Source: World Health Organization Map Production: Information, Evidence and Research (IER) World Health Organization

Fig. 5. Prevalence of raised blood pressure in male adults (18 years or older) according to World Health Organization (WHO) with data from 2015 (Data from Global Health Observatory Map Gallery, WHO with original copyright holder's permission; http://gamapserver.who.int/mapLibrary/ Files/Maps/Global_BloodPressurePrevalence_2015_Male.png, accessed in 2018 June 25).

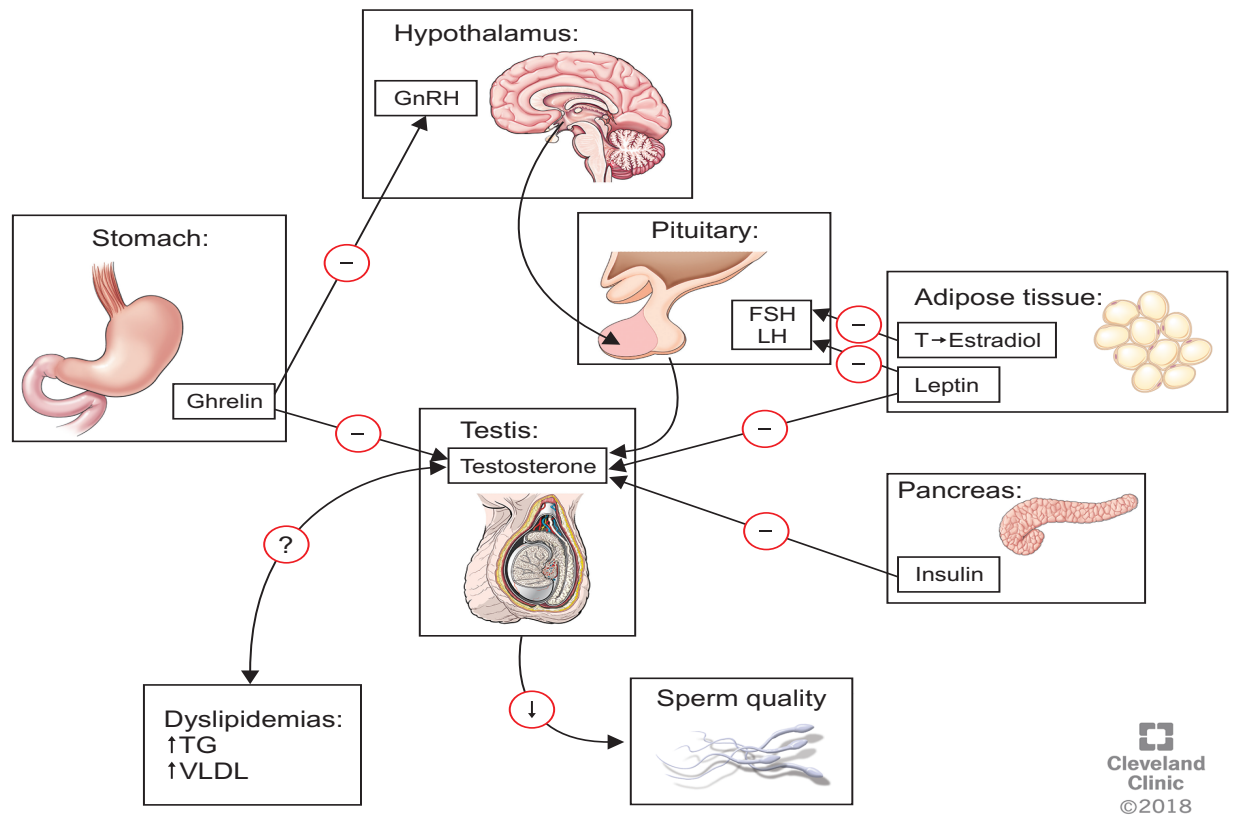

Fig. 6. Hormonal regulation of the hypothalamus-pituitary-gonad by hormones affected by metabolic syndrome in man. $\mathrm{GnRH}$ : gonadotropin-releasing hormone, FSH: follicle-stimulating hormone, LH: luteinizing hormone, TG: triglycerides, VLDL: very low density lipoproteins. 
and weight (weight per height squared, $\mathrm{kg} / \mathrm{m}^{2}$ ) [21]. The WHO defines overweight and obesity when the BMI is $\geq 25 \mathrm{~kg} / \mathrm{m}^{2}$ and $\geq 30 \mathrm{~kg} / \mathrm{m}^{2}$, respectively [22]. Obesity is further divided into three classes; class I (BMI, $30.0-34.9 \mathrm{~kg} / \mathrm{m}^{2}$ ), class II (BMI, $35.0-39.9 \mathrm{~kg} / \mathrm{m}^{2}$ ), and class III (BMI, $\geq 40.0 \mathrm{~kg} / \mathrm{m}^{2}$ ) [21,23]. Obesity can also be diagnosed based on abdominal fat defined as WC $\geq 102$ $\mathrm{cm}$ for men and $\mathrm{WC} \geq 88 \mathrm{~cm}$ for women [24]. The origin of obesity is multifactorial, and involves an interaction between the environment, genetic backgrounds, and hormones [25]. Many hormones are involved in the patho-etiology of obesity especially that the adipose tissue is now recognized as an endocrine organ with its excess being a cause for comorbidities (Fig. 1) [26]. Obesity results from excessive accumulation of adipose tissue and consequently weight gain, because of an imbalance between energy intake and expenditure [26,27].

Leptin, a hormone produced by the adipose tissue [28], regulates energy homeostasis [29] and is an essential intermediary of inflammation in obesity [30]. Obese men develop leptin resistance and hence have high levels of leptin in their circulation [31]. Ghrelin, a hormone secreted by the stomach, is responsible for regulating appetite [32] and is negatively correlated with BMI, meaning that it is lower in the obese [32]. Peptide YY (PYY), glucagon like peptide-1 (GLP-1), and cholecystokinin (CCK) are produced by the gastrointestinal tract after food intake [21], augmenting satiety [33]. Obese people secrete lower levels of PYY, GLP-1, and CCK in comparison to people with normal weight [34,35] (Fig. 1).

The hormonal disturbances causing obesity can have genetic and congenital backgrounds, such as PraderWill syndrome, leptin deficiency, and Cohen syndrome among others. The ingestion of extreme amounts of food increases inflammation [36], which is also observed with the excessive consumption of salt, sugars, alcohol, and fats [37]. This, coupled with smoking and lazy lifestyle, places obese people at risk for a number of chronic diseases, such as hypertension, cancer, and diabetes. The increase in the BMI has been associated with an increase in risk of developing myeloma, leukemia, rectum, thyroid, kidney, colon, and esophageal cancer [38].

\section{The link between obesity and male fertility}

Recent reports showed a relationship between an increase in obesity rates and a decrease in birth rates. The effects of overweight and obesity on male fertility is a hot topic in our days with a good number of studies reporting significant effects of excessive weight on semen parameters and/or hormonal profile of men (Fig. 1).

A systematic review of 21 cross-sectional and prospective cohort studies originating from 12 countries and including a total of 13,077 individuals recruited from the general population or fertility clinics was conducted to assess the relationship between sperm count and BMI. The authors found a J-shaped association between BMI and abnormal sperm count. Compared with men of normal weight, the odds ratios (95\% confidence interval) for oligozoospermia were 1.11 (1.01-1.21) for overweight men, 1.28 (1.06-1.55) for obese men, and 2.04 (1.59-2.62) for morbidly obese men. This meta-analysis quantifies a two-fold increase in risk of oligozoospermia in morbidly obese men [39]. More recent studies have also confirmed this negative association between BMI and various semen parameters. Tang et al [40] assessed the correlation between BMI and semen analysis parameters of infertile patients finding a significant negative correlation between BMI and sperm motility. Another study of similar design reported significant negative correlation between BMI and sperm concentration [41]. Bieniek et al [42] conducted a multi-institutional study including infertile men looking for a relationship between semen and hormone parameters and the patients' BMI. The authors found a significant inverse relationship between BMI and sperm concentration, sperm morphology, total testosterone, and testosterone: estradiol ratio. Studies exploring the impact of BMI on advanced sperm function test also have yielded detrimental effects where a significantly increased rate of sperm DNA damage and lower mitochondrial activity have been observed in obese men compared with men of normal weight [43,44]. Furthermore, the impact of obesity on sex hormone levels has been more evidently acknowledged with a negative correlation between total or free testosterone [45-47], luteinizing hormone (LH) [45,46], SHBG [46,47], inhibin B [47], and AMH [47] and increasing BMI have been reported .

Overall, a clear association between altered sperm parameters, DNA fragmentation and fluctuations in hormonal levels and obesity was detected by several studies. The effects of obesity on male fertility and sperm functions can occur as a consequence of several mechanisms: i) an imbalance between testosterone and estradiol ratio and consequently other sexual hormones 
due to the excessive aromatization in adipocytes; ii) excessive inflammation and oxidative stress resulting from the high levels of adipokines and toxins in adipose tissue of obese men; iii) increase of gonadal temperature due to an accumulation of fat tissue in the scrotal region impairing spermatogenesis; iv) dysregulation of several hormones, such as leptin that can alter the hypothalamus-pituitary-gonad (HPG) axis (Fig. 1, 6).

The maintenance of testosterone levels is crucial for male fertility status (Fig. 6). The link between obesity and testosterone deficiency is supported by many studies [45-47]. Testosterone levels in obese males are commonly related with levels similar to hypogonadal men $[21,48]$. In obese men, an increase in the activity of aromatase enzyme in the adipocytes results in the peripheral conversation of testosterone into estradiol $[21,48]$. Once the levels of estradiol rise, a negative feedback on LH secretion is observed, leading to the suppression of the HPG axis and consequently a reduction in testosterone production by Leydig cells [48]. Estradiol also plays a critical role in the development of germ cells and variations in levels of estrogen can affect spermatogenesis (for review [49]). Adipocytes are the main producers of leptin, and this hormone per se affects $\mathrm{LH}$ and follicle-stimulating hormone (FSH) release from the pituitary, altering not only the amplitude of the released pulses, but also the pulsatility; this affects the balance of the HPG axis in case of excess of adipose tissue [50,51]. The deposition of fat tissue around the scrotal vessels can reduce spermatogenesis in obese men decreasing blood cooling and consequently increasing testicular temperature [52,53]. The relationship between scrotal lipomatosis and male infertility was described in a study that confirmed a diffuse pattern of fat deposition around the structures of the spermatic cord in obese men [52]. Another study showed an improvement of sperm quality after a scrotal or suprapubic lipectomy [53]. More recent studies explored the connection between oxidative stress and the fertility status of obese men. Oxidative stress is an acknowledged cause of sperm dysfunction as it causes sperm membrane lipid peroxidation, DNA fragmentation, and aggravates apoptosis [54]. Obese men are particularly prone to oxidative stress. The excess in adipose tissue is associated with an increase in local and systemic production of pro-inflammatory adipocytokines [55], which induce the production of reactive oxygen species (ROS).
Furthermore, increased oxidative stress leads to important changes in adipose tissue, promoting a systemic low-grade inflammatory response with adverse effects throughout the body including the reproductive tract (for review [56]). Finally, ED is another important factor to consider in patients seeking fertility. Obese men are at higher risk of ED [57] due to lower testosterone levels and high levels of inflammatory factors [58,59].

\section{GLUCOSE METABOLISM AND MALE FERTILITY}

\section{An overview on the impairment of glucose metabolism}

The maintenance of plasma glucose is crucial for the physiological functions of the body. Glucose is the sole energy fuel for cells protected by blood-barriers, such as the brain [60] and testes [61]. The diagnosis of glucose impairment is achieved through monitoring glucose levels in blood stream, such as measuring the fasting glucose or with an oral glucose tolerance test. For the measurement of fasting glucose, the cut point for prediabetes is $100-125 \mathrm{mg} / \mathrm{dL}$, while that for diabetes mellitus (DM) is $\geq 126 \mathrm{mg} / \mathrm{dL}$ [62]. After an oral glucose tolerance test, prediabetes is diagnosed when the blood sugar is 140-199 mg/dL and DM is diagnosed when the blood sugar is $\geq 200 \mathrm{mg} / \mathrm{dL}$ [62]. Hypoglycemia is defined as abnormally low glucose concentration that is harmful for the patient with values $<70 \mathrm{mg} / \mathrm{dL}$ considered alerting. On the other hand, hyperglycemia is detrimental to human health as a slight increase in plasma glucose concentrations can raise the risk of cardiovascular diseases. While obesity is considered a major risk factor for dysregulation of glucose metabolism, other environmental and genetic factors can also contribute to this condition [63]. Impairment of glucose metabolism is a key component of MetS. Insulin is the principle regulator of glucose metabolism. This hormone is produced by the pancreatic $\beta$-cells to facilitate uptake of glucose from the blood stream into cells and tissues. Insulin resistance is defined as the reduced sensitivity of cells to stimulation by insulin in normal or elevated levels of glucose. As a result, the pancreas will secrete more insulin, resulting in a state of hyperinsulinemia. With continued insulin resistance, hyperglycemia ensues, causing glucose intolerance and finally type $2 \mathrm{DM}$ (T2DM) (for review [63]). 


\section{The link between impairment of glucose and male fertility}

Similar to obesity, studies demonstrated a correlation between the increase in the incidence of DM and a decrease in the fertility rates [64]. A study comparing patients with T2DM to non-diabetic men attending a fertility clinic showed lower progressive motility and an increase in sperm DNA fragmentation in diabetic patients [65]. Also the clinical pregnancy rate and the miscarriage rate was higher when the male partner was diabetic [65]. Another study of similar design also confirmed the presence of lower sperm concentration and total count in semen of diabetic patients compared with healthy individuals [66]. A study conducted in normozoospermic T2DM and non-diabetic men detected higher levels of malondialdehyde, a marker of oxidative stress, in diabetic patients that was consistent with lower sperm concentration, motility and normal morphology in this group compared with non-diabetic men [67]. In addition to the negative effects on sperm count, motility, and DNA integrity, lower ejaculate volumes were also observed in diabetic men [68]. The aforementioned studies provide solid evidence on the negative effects of diabetes on male fertility. The pathophysiology of these effects have been studied in a number of human and animal models and are believed to occur secondary to alterations in testicular environment, testosterone homeostasis, ejaculatory function, and libido (for review [69]).

Testicular environment is highly controlled by glucose homeostasis that can be deregulated in DM thereby impairing spermatogenesis [70,71]. Animal studies reported excessive damage to seminiferous tubules early in the development of DM impairing the gonadosomatic index, as well as sperm quality [72]. Experimental induction of DM in mice resulted in enhanced lipid peroxidation in testis (cytosol and mitochondria) and epididymal sperm and increased ROS production as early as 5 days following the experiment [73]. This suggests that oxidative stress is increased in diabetes due to overproduction of ROS. Associated with the ROS generation is a decreased efficiency of antioxidant defenses, which is a process that starts very early and worsens over the course of the disease. Many studies have focused on the derangement in testosterone levels in men presenting with DM (Fig. 6). A causeeffect relationship exists between testosterone and DM where lower levels of testosterone are typically pres- ent in diabetic men, increasing the risk for developing T2DM occurs when testosterone concentrations are low (for review [74]). This is because testosterone improves insulin sensitivity and hence glucose homeostasis. Testosterone is also an important regulator of spermatogenesis as a number of genes and kinases on Sertoli cells are directly influenced by testosterone levels [75]. Therefore, the decreased testosterone levels could help explain the alteration in sperm production seen in diabetic patients. Sexual dysfunctions such as erectile and ejaculatory dysfunction as well as decreased libido are common in patients with DM [76]. Retrograde ejaculation (RE) occurs as a consequence of a diabetic autonomic neuropathy [77]. It has a devastating effect on male fertility potential as it decreases the ejaculate volume and hence the sperm quantity. The sympathetic nervous system plays an important role during emission and expulsion phases of ejaculation. It orchestrates smooth muscle contraction of the seminal vesicles and ejaculatory ducts and simultaneously ensures bladder neck closure to prohibit retrograde flow of semen into the bladder. Sympathetic nervous system dysfunction has been detected in patients with DM resulting in RE (for review [78]). One study reported the presence of RE in $34.6 \%$ of diabetic men in comparison to $0 \%$ in nondiabetic men, demonstrating the presence of aspermia in diabetic men with $\mathrm{RE}$ [77]. $\mathrm{ED}$ is more prevalent in diabetic men compared with the general population [79]. Diabetic patients are prone to neurovascular alterations which can induce impairment of the endothelial function of the corpus cavernosum and therefore result in organic ED [80,81]. Endothelial dysfunctions are a reflection of decrease/loss of nitric oxide (NO) biological activity and/or biosynthesis at endothelial level [82]. Although, in diabetic men, the pathogenic mechanisms of endothelial function still remain unclear; impairment of NO activity, an essential molecule for penile vascular and cavernous smooth muscle activity has been observed in diabetic men [83].

\section{DYSLIPIDEMIA AND MALE INFERTILITY}

\section{An overview on dyslipidemia}

Dyslipidemia is defined as the abnormal amount of lipids including triglycerides, cholesterol, and fat phospholipids in the blood steam (Fig. 1). It can occur primarily due to several genetic disorders or secondary 
to environmental factors or other diseases. The elevation of biochemical makers in blood analysis such as total cholesterol and low-density lipoprotein cholesterol (LDL-C) received more attention as they are particularly sensitive to lifestyle changes [84]. Other biochemical markers of importance in dyslipidemias are the very low density lipoproteins (VLDL), triglycerides, and the high-density lipoprotein-cholesterol (HDL-C) levels [84]. The production of lipoproteins is regulated by substrate supply and hormonal levels. Insulin and glucagon are essential hormones involved in the regulation of lipoprotein production [85]; however the exact role of these hormones remains to be elucidated. On the other hand, the availability of substrates regulates gene expression in lipid metabolism. Some transcriptional factors such as hepatic nuclear factor, retinoid $\mathrm{X}$ receptor, peroxisome proliferator activated receptor, were identified as targets for fatty acids (for review [86]). Screening of the lipid profile is recommended for men over the age of 40 years, individuals presenting risk factors for atherosclerosis, such as diabetes, hypertension, obesity, some autoimmune chronic inflammatory conditions, among other medical conditions, and in case of hereditary dyslipidemia. Assessing the lipid profile is a method of dyslipidemia evaluation, which encloses the determination of total cholesterol, LDL-C, apolipoprotein B, nonHDL-C and triglycerides.

\section{The link between dyslipidemia and male fertility}

The role of cholesterol in post-testicular modification of sperm plasma membrane composition and dynamics is essential for fertility; however, the impact of high cholesterol and other dyslipidemias in fertility remains to be elucidated (Fig. 6). Aiming to evaluate the association between men's serum lipid concentrations and semen quality parameters, Schisterman et al [87] examined semen samples from male partners of couples desiring pregnancy. The authors detected higher levels of serum total cholesterol, free cholesterol, and phospholipids in patients with a significantly lower percentage of spermatozoa with intact acrosome and smaller sperm head area. In another study, the same authors observed higher levels of cholesterol in couples who had a significantly longer time to conception [87]. Hagiuda et al [88] assessed the relationship between dyslipidemia and sperm quality and serum hormone levels in male patients in Japan. Serum triglyceride level had a positive association with sperm morphologic traits and a negative association with serum testosterone level. Another study reported that VLDL, in addition to serum triglycerides, had an inverse relationship with sperm motility proposing that these lipids, in excess, may have deleterious effects on spermatogenesis [89]. Oxidative stress, which often accompanies the derangement in serum lipid concentration, may be the driving force behind the impact that dyslipidemia has on male fertility. This hypothesis was supported by the work of Shalaby et al [90] who examined the effects of highcholesterol diet and anti-cholesterol therapy on male rat fertility. The authors demonstrated significant decline of fertility, testicular weight, and sperm parameters in male rats fed with a high-cholesterol diet compared to a cholesterol-free diet. Male rats on a highcholesterol diet were then treated with no-intervention, alpha-tocopherol (an antioxidant), simvastatin (a lipidlowering agent), or both therapeutic agents. Treatment with alpha-tocopherol, simvastatin, and the two in combination significantly increased testicular weight and sperm parameters together with an improvement in fertility index (mating success rate). This improvement was more prominent with combination therapy compared with both individual therapies. The authors not only demonstrated decreased fertility with a highcholesterol diet, but they also showed therapeutic gain in fertility with antioxidant and lipid-lowering agents.

\section{HYPERTENSION AND MALE INFERTILITY}

\section{An overview on hypertension}

Hypertension, a disease of the vascular system, results from the improper functioning of the arterial pressure control mechanisms. Hypertension is diagnosed when systolic pressure $>140 \mathrm{mmHg}$ or diastolic pressure $>90 \mathrm{mmHg}$ during repeated measurements of blood pressure. Hypertension can be classified into different grades, according to the European Society for Hypertension/European Society for Cardiology where grade 1 is considered when the systolic pressure is $140-159 \mathrm{mmHg}$ and the diastolic pressure is $90-99$ mmHg; Grade 2 when the systolic pressure is $160-179$ $\mathrm{mmHg}$ and the diastolic pressure is $100-109 \mathrm{mmHg}$; Grade 3 when the systolic pressure is $\geq 180 \mathrm{mmHg}$ and the diastolic pressure is $\geq 100 \mathrm{mmHg}$ [91]. Hypertension is a multifactorial disease, and the development of this 
condition has some risk factors such as: food habits, lifestyle, ethnic, and genetic predisposition.

\section{The link between hypertension and male fertility}

Existing data suggest an association between hypertension and impaired semen quality. Guo et al [92] revealed that men with hypertension had lower semen volume, motility, total count, and total motile count when compared with men without hypertension. In an attempt to study the relationship between semen quality and current health status, Eisenberg et al [93] described higher rates of semen abnormalities in men with diseases in the circulatory system particularly hypertensive disease, peripheral vascular disease, and non-ischemic heart disease. Such an association was not thoroughly investigated and the direct end-organ effects of hypertension on the testes is not well characterized. Theories linking hypertension with reproductive dysfunction are mainly based on endocrine derangements or ED that may accompany this disease. A cross-sectional study identified a negative correlation between testosterone and systolic blood pressure [94]. This finding was replicated in another case-control study by Fogari et al [95] who quantified a 10\% reduction in total testosterone levels in hypertensive men compared to normotensive men. ED is more prevalent in hypertensive men with a 2 -fold increased risk than the general population [96-98]. The causes are related to structural lesions that result from high blood pressure in penile arteries which are aggravated by atherosclerosis resulting in impairment of blood flow [99,100]. Again, compelling evidence linking hypertension to impairment in testicular function is still lacking and requires further experimental research.

\section{DOES THE TREATMENT OF METABOLIC SYNDROME AFFECTS FERTILITY?}

Weight loss through adoption of a healthy lifestyle in addition to regular physical activity is the cornerstone treatment for MetS. An improvement in sperm quality is expected as weight reduction would alleviate the previously mentioned deleterious effects of obesity on human reproduction. This belief has been proven in studies that explored the effect of natural weight reduction on male fertility. Håkonsen et al [101] studied semen samples men with BMI $>33 \mathrm{~kg} / \mathrm{m}^{2}$ who underwent a 14-week weight loss program. Following the intervention, the median percentage weight loss was $15 \%$. An increase in total sperm count, semen volume, testosterone, SHBG, and AMH were also observed. A larger study by Jaffar [102] included obese men who underwent diet counselling and exercise resulting in mean BMI loss of $2.2 \mathrm{~kg} / \mathrm{m}^{2}$. The author observed a significant positive correlation between weight loss and percentage of progressive sperm motility and static percentage. On the other hand, the effect of weight loss following bariatric surgery on semen parameters and male fertility is still controversial with some studies reporting no or worse influence while others finding an improvement in semen parameters following bariatric surgery. The imbalance in electrolytes and nutrients observed after these mal-absorptive surgeries may explain the observed worsening in semen parameters that occur shortly after surgery [103,104]. However, newer evidence detected significant improvements in semen parameters with longer periods of follow-up after surgery [105].

\section{CONCLUSIONS}

MetS is increasing worldwide almost approaching the pandemic state. Its key components, namely, obesity, insulin resistance, dyslipidemia, and hypertension can have detrimental effects on various aspects of human health. Male fertility is one condition that can be influenced by MetS through several mechanisms. Endocrine system dysregulation, scrotal temperature elevation, oxidative stress, and alteration of the erectile and ejaculatory functions are well recognized MetS consequences that can impair sperm production and function, ultimately affecting male fertility. A healthy lifestyle characterized by good nutrition and regular physical activity is key to prevent the unwanted effects of MetS not only on fecundity but also on health and well-being overall.

\section{ACKNOWLEDGEMENTS}

This study was supported by American Center for Reproductive Medicine. Ana Dias Martins was funded by the "Fundação para a Ciência e Tecnologia" (SFRH/ BD/108726/2015) and Fulbright (ID: E0585654). 


\section{Disclosure}

The authors have no potential conflicts of interest to disclose.

\section{Author Contribution}

Conceptualization: all the authors. Data acquisition: Martins AD. Formal analysis: all the authors. Writing (original draft): Martins AD. Writing (review \& editing): all the authors. Approval of the final manuscript: all the authors.

\section{REFERENCES}

1. Kylin E. Studien ueber das Hypertonie-Hyperglyka "mieHyperurika" miesyndrom. Zentbl Inn Med 1923;44:105-27.

2. Vague J. Sexual differentiation, a factor affecting the forms of obesity. Presse Med 1947;30:339-40.

3. Haller H, Hanefeld M. Synoptische Betrachtung metabolischer Risikofaktoren. Haller H, Hanefeld M, Jaross W, editors. Lipidstoffwechselstörungen. Jena: Gustav Fischer Verlag; 1975;254-64.

4. Reaven GM. Banting lecture 1988. Role of insulin resistance in human disease. Diabetes 1988;37:1595-607.

5. Kaplan NM. The deadly quartet. Upper-body obesity, glucose intolerance, hypertriglyceridemia, and hypertension. Arch Intern Med 1989;149:1514-20.

6. Haffner SM, Valdez RA, Hazuda HP, Mitchell BD, Morales PA, Stern MP. Prospective analysis of the insulin-resistance syndrome (syndrome X). Diabetes 1992;41:715-22.

7. Alberti KG, Zimmet P, Shaw J. Metabolic syndrome: a new world-wide definition. A Consensus Statement from the International Diabetes Federation. Diabet Med 2006;23:469-80.

8. Expert Panel on Detection, Evaluation, and Treatment of High Blood Cholesterol in Adults. Executive summary of The Third Report of The National Cholesterol Education Program (NCEP) expert panel on detection, evaluation, and treatment of high blood cholesterol in adults (Adult Treatment Panel III). JAMA 2001;285:2486-97.

9. Consultation W. Definition, diagnosis and classification of diabetes mellitus and its complications: report of a WHO consultation. Part 1. Geneva: World Health Organization; 1999.

10. Balkau B, Charles MA. Comment on the provisional report from the WHO consultation. European Group for the Study of Insulin Resistance (EGIR). Diabet Med 1999;16:442-3.

11. Garber AJ, Moghissi ES, Bransome ED Jr, Clark NG, Clement $\mathrm{S}$, Cobin RH, et al. American College of Endocrinology position statement on inpatient diabetes and metabolic control.
Endocr Pract 2004;10 Suppl 2:4-9.

12. Alberti KG, Zimmet PZ. Definition, diagnosis and classification of diabetes mellitus and its complications. Part 1: diagnosis and classification of diabetes mellitus provisional report of a WHO consultation. Diabet Med 1998;15:539-53.

13. Ahima RS. Overview of metabolic syndrome. In: Ahima RS, editor. Metabolic syndrome: a comprehensive textbook. Cham: Springer International Publishing; 2016;3-12.

14. Falkner B, Cossrow ND. Prevalence of metabolic syndrome and obesity-associated hypertension in the racial ethnic minorities of the United States. Curr Hypertens Rep 2014;16: 449.

15. Cameron AJ, Shaw JE, Zimmet PZ. The metabolic syndrome: prevalence in worldwide populations. Endocrinol Metab Clin North Am 2004;33:351-7.

16. Lotti F, Corona G, Degli Innocenti S, Filimberti E, Scognamiglio V, Vignozzi L, et al. Seminal, ultrasound and psychobiological parameters correlate with metabolic syndrome in male members of infertile couples. Andrology 2013;1:229-39.

17. Lotti F, Corona G, Vignozzi L, Rossi M, Maseroli E, Cipriani S, et al. Metabolic syndrome and prostate abnormalities in male subjects of infertile couples. Asian J Androl 2014;16:295-304.

18. Leisegang K, Udodong A, Bouic PJ, Henkel RR. Effect of the metabolic syndrome on male reproductive function: a casecontrolled pilot study. Andrologia 2014;46:167-76.

19. Ventimiglia E, Capogrosso P, Colicchia M, Boeri L, Serino A, Castagna G, et al. Metabolic syndrome in white European men presenting for primary couple's infertility: investigation of the clinical and reproductive burden. Andrology 2016;4: 944-51.

20. Ehala-Aleksejev K, Punab M. The effect of metabolic syndrome on male reproductive health: a cross-sectional study in a group of fertile men and male partners of infertile couples. PLoS One 2018;13:e0194395.

21. Pozza C, Isidori AM. What's behind the obesity epidemic. Cham: Imaging in Bariatric Surgery, Springer International Publishing AG; 2018;1-8.

22. World Health Organization. Obesity and overweight fact sheet [Internet]. Geneva: World Health Organization; c2016 [cited 2018 Sep]. Available from: http://www.who.int/newsroom/fact-sheets/detail/obesity-and-overweight.

23. Gadde KM, Martin CK, Berthoud HR, Heymsfield SB. Obesity: pathophysiology and management. J Am Coll Cardiol 2018;71:69-84.

24. Okosun IS, Liao Y, Rotimi CN, Prewitt TE, Cooper RS. Abdominal adiposity and clustering of multiple metabolic syndrome in White, Black and Hispanic Americans. Ann Epidemiol 2000;10:263-70. 
25. Kaila B, Raman M. Obesity: a review of pathogenesis and management strategies. Can J Gastroenterol 2008;22:61-8.

26. Prentice AM, Jebb SA. Beyond body mass index. Obes Rev 2001;2:141-7.

27. Panuganti KK, Lenehan CP. Obesity. Treasure Island (FL): StatPearls; 2017.

28. Halaas JL, Gajiwala KS, Maffei M, Cohen SL, Chait BT, Rabinowitz $\mathrm{D}$, et al. Weight-reducing effects of the plasma protein encoded by the obese gene. Science 1995;269:543-6.

29. Villanueva EC, Myers MG Jr. Leptin receptor signaling and the regulation of mammalian physiology. Int J Obes (Lond) 2008;32 Suppl 7:S8-12.

30. Martin SS, Qasim A, Reilly MP. Leptin resistance: a possible interface of inflammation and metabolism in obesity-related cardiovascular disease. J Am Coll Cardiol 2008;52:1201-10.

31. Crujeiras AB, Carreira MC, Cabia B, Andrade S, Amil M, Casanueva FF. Leptin resistance in obesity: an epigenetic landscape. Life Sci 2015;140:57-63.

32. Tschöp M, Weyer C, Tataranni PA, Devanarayan V, Ravussin E, Heiman ML. Circulating ghrelin levels are decreased in human obesity. Diabetes 2001;50:707-9.

33. Valassi E, Scacchi M, Cavagnini F. Neuroendocrine control of food intake. Nutr Metab Cardiovasc Dis 2008;18:158-68.

34. Alvarez Bartolomé M, Borque M, Martinez-Sarmiento J, Aparicio E, Hernández C, Cabrerizo L, et al. Peptide YY secretion in morbidly obese patients before and after vertical banded gastroplasty. Obes Surg 2002;12:324-7.

35. Murphy KG, Bloom SR. Gut hormones and the regulation of energy homeostasis. Nature 2006;444:854-9.

36. O'Keefe JH, Gheewala NM, O’Keefe JO. Dietary strategies for improving post-prandial glucose, lipids, inflammation, and cardiovascular health. J Am Coll Cardiol 2008;51:249-55.

37. Egger G, Dixon J. Inflammatory effects of nutritional stimuli: further support for the need for a big picture approach to tackling obesity and chronic disease. Obes Rev 2010;11:13749.

38. Gallagher EJ, LeRoith D. Obesity and diabetes: the increased risk of cancer and cancer-related mortality. Physiol Rev 2015; 95:727-48.

39. Sermondade N, Faure C, Fezeu L, Shayeb AG, Bonde JP, Jensen TK, et al. BMI in relation to sperm count: an updated systematic review and collaborative meta-analysis. Hum Reprod Update 2013;19:221-31.

40. Tang WH, Zhuang XJ, Ma LL, Qiao J, Hong K, Zhao LM, et al. Correlation between body mass index and semen quality in male infertility patients. Turk J Med Sci 2015;45:1300-5.

41. Alshahrani S, Ahmed AF, Gabr AH, Abalhassan M, Ahmad $\mathrm{G}$. The impact of body mass index on semen parameters in infertile men. Andrologia 2016;48:1125-9.

42. Bieniek JM, Kashanian JA, Deibert CM, Grober ED, Lo KC, Brannigan RE, et al. Influence of increasing body mass index on semen and reproductive hormonal parameters in a multiinstitutional cohort of subfertile men. Fertil Steril 2016;106: 1070-5.

43. Dupont C, Faure C, Sermondade N, Boubaya M, Eustache F, Clément $\mathrm{P}$, et al. Obesity leads to higher risk of sperm DNA damage in infertile patients. Asian J Androl 2013;15:622-5.

44. Fariello RM, Pariz JR, Spaine DM, Cedenho AP, Bertolla RP, Fraietta R. Association between obesity and alteration of sperm DNA integrity and mitochondrial activity. BJU Int 2012;110:863-7.

45. Al-Ali BM, Gutschi T, Pummer K, Zigeuner R, BrookmanMay S, Wieland WF, et al. Body mass index has no impact on sperm quality but on reproductive hormones levels. Andrologia 2014;46:106-11.

46. Macdonald AA, Stewart AW, Farquhar CM. Body mass index in relation to semen quality and reproductive hormones in New Zealand men: a cross-sectional study in fertility clinics. Hum Reprod 2013;28:3178-87.

47. Andersen JM, Herning H, Aschim EL, Hjelmesæth J, Mala T, Hanevik HI, et al. Body mass index is associated with impaired semen characteristics and reduced levels of anti-müllerian hormone across a wide weight range. PLoS One 2015;10: e0130210.

48. Repaci A, Pasquali R. Reproductive disorders and obesity in males and females and focus on the polycystic ovary syndrome. Metabolic syndrome: a comprehensive textbook. Cham: Springer International Publishing AG; 2014;1-19.

49. O’Shaughnessy PJ. Hormonal control of germ cell development and spermatogenesis. Semin Cell Dev Biol 2014;29:5565.

50. Vermeulen A, Kaufman JM, Deslypere JP, Thomas G. Attenuated luteinizing hormone $(\mathrm{LH})$ pulse amplitude but normal $\mathrm{LH}$ pulse frequency, and its relation to plasma androgens in hypogonadism of obese men. J Clin Endocrinol Metab 1993; 76:1140-6.

51. George JT, Millar RP, Anderson RA. Hypothesis: kisspeptin mediates male hypogonadism in obesity and type 2 diabetes. Neuroendocrinology 2010;91:302-7.

52. Shafik A, Olfat S. Scrotal lipomatosis. Br J Urol 1981;53:50-4.

53. Shafik A, Olfat S. Lipectomy in the treatment of scrotal lipomatosis. Br J Urol 1981;53:55-61.

54. Kodama H, Yamaguchi R, Fukuda J, Kasai H, Tanaka T. Increased oxidative deoxyribonucleic acid damage in the spermatozoa of infertile male patients. Fertil Steril 1997;68:51924. 
55. Sengenès $\mathrm{C}$, Miranville $\mathrm{A}$, Lolmède $\mathrm{K}$, Curat $\mathrm{CA}$, Bouloumié A. The role of endothelial cells in inflamed adipose tissue. J Intern Med 2007;262:415-21.

56. Rzheshevsky AV. Fatal "triad": lipotoxicity, oxidative stress, and phenoptosis. Biochemistry (Mosc) 2013;78:991-1000.

57. Feldman HA, Johannes CB, Derby CA, Kleinman KP, Mohr $\mathrm{BA}$, Araujo AB, et al. Erectile dysfunction and coronary risk factors: prospective results from the Massachusetts male aging study. Prev Med 2000;30:328-38.

58. Burnett AL, Strong TD, Trock BJ, Jin L, Bivalacqua TJ, Musicki B. Serum biomarker measurements of endothelial function and oxidative stress after daily dosing of sildenafil in type 2 diabetic men with erectile dysfunction. J Urol 2009;181:24551.

59. Araña Rosaínz Mde J, Ojeda MO, Acosta JR, Elías-Calles LC, González NO, Herrera OT, et al. Imbalanced low-grade inflammation and endothelial activation in patients with type 2 diabetes mellitus and erectile dysfunction. J Sex Med 2011;8: 2017-30.

60. Mergenthaler P, Lindauer U, Dienel GA, Meisel A. Sugar for the brain: the role of glucose in physiological and pathological brain function. Trends Neurosci 2013;36:587-97.

61. Rato L, Alves MG, Socorro S, Duarte AI, Cavaco JE, Oliveira PF. Metabolic regulation is important for spermatogenesis. Nat Rev Urol 2012;9:330-8.

62. American Diabetes Association. 2. Classification and diagnosis of diabetes: standards of medical care in diabetes-2018. Diabetes Care 2018;41:S13-27.

63. Skyler JS, Bakris GL, Bonifacio E, Darsow T, Eckel RH, Groop $\mathrm{L}$, et al. Differentiation of diabetes by pathophysiology, natural history, and prognosis. Diabetes 2017;66:241-55.

64. Lutz W. Fertility rates and future population trends: will Europe's birth rate recover or continue to decline? Int J Androl 2006;29:25-33.

65. Rama Raju GA, Jaya Prakash G, Murali Krishna K, Madan K, Siva Narayana T, Ravi Krishna CH. Noninsulin-dependent diabetes mellitus: effects on sperm morphological and functional characteristics, nuclear DNA integrity and outcome of assisted reproductive technique. Andrologia 2012;44 Suppl 1: 490-8.

66. An T, Wang YF, Liu JX, Pan YY, Liu YF, He ZC, et al. Comparative analysis of proteomes between diabetic and normal human sperm: insights into the effects of diabetes on male reproduction based on the regulation of mitochondria-related proteins. Mol Reprod Dev 2018;85:7-16.

67. Singh AK, Tomarz S, Chaudhari AR, Sinqh R, Verma N. Type 2 diabetes mellitus affects male fertility potential. Indian J Physiol Pharmacol 2014;58:403-6.
68. Bhattacharya SM, Ghosh M, Nandi N. Diabetes mellitus and abnormalities in semen analysis. J Obstet Gynaecol Res 2014; 40:167-71.

69. Jangir RN, Jain GC. Diabetes mellitus induced impairment of male reproductive functions: a review. Curr Diabetes Rev 2014;10:147-57.

70. Oliveira PF, Alves MG, Rato L, Silva J, Sá R, Barros A, et al. Influence of $5 \alpha$-dihydrotestosterone and $17 \beta$-estradiol on human Sertoli cells metabolism. Int J Androl 2011;34:e612-20.

71. Alves MG, Rato L, Carvalho RA, Moreira PI, Socorro S, Oliveira PF. Hormonal control of Sertoli cell metabolism regulates spermatogenesis. Cell Mol Life Sci 2013;70:777-93.

72. Seethalakshmi L, Menon M, Diamond D. The effect of streptozotocin-induced diabetes on the neuroendocrine-male reproductive tract axis of the adult rat. J Urol 1987;138:190-4.

73. Shrilatha B, Muralidhara. Early oxidative stress in testis and epididymal sperm in streptozotocin-induced diabetic mice: its progression and genotoxic consequences. Reprod Toxicol 2007;23:578-87.

74. Beatrice AM, Dutta D, Kumar M, Kumbenahalli Siddegowda S, Sinha A, Ray S, et al. Testosterone levels and type 2 diabetes in men: current knowledge and clinical implications. Diabetes Metab Syndr Obes 2014;7:481-6.

75. Walker WH. Molecular mechanisms of testosterone action in spermatogenesis. Steroids 2009;74:602-7.

76. Burke JP, Jacobson DJ, McGree ME, Nehra A, Roberts RO, Girman CJ, et al. Diabetes and sexual dysfunction: results from the Olmsted County study of urinary symptoms and health status among men. J Urol 2007;177:1438-42.

77. Fedder J, Kaspersen MD, Brandslund I, Højgaard A. Retrograde ejaculation and sexual dysfunction in men with diabetes mellitus: a prospective, controlled study. Andrology 2013; 1:602-6.

78. Vinik AI, Maser RE, Mitchell BD, Freeman R. Diabetic autonomic neuropathy. Diabetes Care 2003;26:1553-79.

79. De Young L, Yu D, Bateman RM, Brock GB. Oxidative stress and antioxidant therapy: their impact in diabetes-associated erectile dysfunction. J Androl 2004;25:830-6.

80. Herman A, Adar R, Rubinstein Z. Vascular lesions associated with impotence in diabetic and nondiabetic arterial occlusive disease. Diabetes 1978;27:975-81.

81. Blanco R, Saenz de Tejada I, Goldstein I, Krane RJ, Wotiz $\mathrm{HH}$, Cohen RA. Dysfunctional penile cholinergic nerves in diabetic impotent men. J Urol 1990;144:278-80.

82. Musicki B, Burnett AL. Endothelial dysfunction in diabetic erectile dysfunction. Int J Impot Res 2007;19:129-38.

83. Saenz de Tejada I, Goldstein I, Azadzoi K, Krane RJ, Cohen RA. Impaired neurogenic and endothelium-mediated relax- 


\section{Men's Health}

ation of penile smooth muscle from diabetic men with impotence. N Engl J Med 1989;320:1025-30.

84. Catapano AL, Reiner Z, De Backer G, Graham I, Taskinen $\mathrm{MR}$, Wiklund $\mathrm{O}$, et al. ESC/EAS Guidelines for the management of dyslipidaemias: the Task Force for the management of dyslipidaemias of the European Society of Cardiology (ESC) and the European Atherosclerosis Society (EAS). Atherosclerosis 2011;217 Suppl 1:S1-44.

85. Longuet C, Sinclair EM, Maida A, Baggio LL, Maziarz M, Charron $\mathrm{MJ}$, et al. The glucagon receptor is required for the adaptive metabolic response to fasting. Cell Metab 2008;8: 359-71.

86. Pégorier JP, Le May C, Girard J. Control of gene expression by fatty acids. J Nutr 2004;134:2444S-9S.

87. Schisterman EF, Mumford SL, Browne RW, Barr DB, Chen Z, Louis GM. Lipid concentrations and couple fecundity: the LIFE study. J Clin Endocrinol Metab 2014;99:2786-94.

88. Hagiuda J, Ishikawa H, Furuuchi T, Hanawa Y, Marumo K. Relationship between dyslipidaemia and semen quality and serum sex hormone levels: an infertility study of 167 Japanese patients. Andrologia 2014;46:131-5.

89. Ergün A, Köse SK, Aydos K, Ata A, Avci A. Correlation of seminal parameters with serum lipid profile and sex hormones. Arch Androl 2007;53:21-3.

90. Shalaby MA, el-Zorba HY, Kamel GM. Effect of alpha-tocopherol and simvastatin on male fertility in hypercholesterolemic rats. Pharmacol Res 2004;50:137-42.

91. O'Shea PM, Griffin TP, Fitzgibbon M. Hypertension: the role of biochemistry in the diagnosis and management. Clin Chim Acta 2017;465:131-43.

92. Guo D, Li S, Behr B, Eisenberg ML. Hypertension and male fertility. World J Mens Health 2017;35:59-64.

93. Eisenberg ML, Li S, Behr B, Pera RR, Cullen MR. Relationship between semen production and medical comorbidity. Fertil Steril 2015;103:66-71.

94. Svartberg J, von Mühlen D, Schirmer H, Barrett-Connor E, Sundfjord J, Jorde R. Association of endogenous testosterone with blood pressure and left ventricular mass in men. The Tromsø Study. Eur J Endocrinol 2004;150:65-71.
Ana Dias Martins, et al: Metabolic Syndrome and Male Fertility

95. Fogari R, Zoppi A, Preti P, Rinaldi A, Marasi G, Vanasia A, et al. Sexual activity and plasma testosterone levels in hypertensive males. Am J Hypertens 2002;15:217-21.

96. Burchardt M, Burchardt T, Baer L, Kiss AJ, Pawar RV, Shabsigh A, et al. Hypertension is associated with severe erectile dysfunction. J Urol 2000;164:1188-91.

97. Thompson IM, Tangen CM, Goodman PJ, Probstfield JL, Moinpour CM, Coltman CA. Erectile dysfunction and subsequent cardiovascular disease. JAMA 2005;294:2996-3002.

98. Ponholzer A, Temml C, Mock K, Marszalek M, Obermayr R, Madersbacher S. Prevalence and risk factors for erectile dysfunction in 2869 men using a validated questionnaire. Eur Urol 2005;47:80-5; discussion 85-6.

99. Toblli JE, Stella I, Inserra F, Ferder L, Zeller F, Mazza ON. Morphological changes in cavernous tissue in spontaneously hypertensive rats. Am J Hypertens 2000;13:686-92.

100. Ushiyama M, Morita T, Kuramochi T, Yagi S, Katayama S. Erectile dysfunction in hypertensive rats results from impairment of the relaxation evoked by neurogenic carbon monoxide and nitric oxide. Hypertens Res 2004;27:253-61.

101. Håkonsen LB, Thulstrup AM, Aggerholm AS, Olsen J, Bonde JP, Andersen CY, et al. Does weight loss improve semen quality and reproductive hormones? Results from a cohort of severely obese men. Reprod Health 2011;8:24.

102. Jaffar M. Does weight loss improve fertility with respect to semen parameters? Results from a large cohort study. Int J Infertil Fetal Med 2016;7:94-9.

103. Reis LO, Zani EL, Saad RD, Chaim EA, de Oliveira LC, Fregonesi A. Bariatric surgery does not interfere with sperm quality: a preliminary long-term study. Reprod Sci 2012;19:105762

104. Buchwald H, Avidor Y, Braunwald E, Jensen MD, Pories W, Fahrbach K, et al. Bariatric surgery: a systematic review and meta-analysis. JAMA 2004;292:1724-37.

105. El Bardisi H, Majzoub A, Arafa M, AlMalki A, Al Said S, Khalafalla $K$, et al. Effect of bariatric surgery on semen parameters and sex hormone concentrations: a prospective study. Reprod Biomed Online 2016;33:606-11. 